Volume 14 - Número 2 - ago/dez de 2019

\title{
MULTIMODALIDADE EM LIVRO DIDÁTICO DO ENSINO FUNDAMENTAL E SEU PAPEL NO LETRAMENTO VISUAL
}

\section{MULTIMODALITY IN A TEXTBOOK FOR ELEMENTARY SCHOOL AND ITS ROLE IN VISUAL LITERACY}

\author{
Orlando Vian Jr. ${ }^{1}$ \\ Jandira de Oliveira Costa ${ }^{2}$
}

\begin{abstract}
RESUMO: Este texto apresenta uma análise dos elementos multimodais na abertura de três unidades de um livro didático de língua portuguesa para o ensino fundamental. O ponto de partida para a análise é a noção de multimodalidade. Tomando a proposta da Análise do Discurso Multimodal Sistêmico-Funcional de Painter, Martin e Unsworth (2013), analisamos aspectos relacionados à (i) Integração Intermodal, isto é, à forma como o modo verbal se integra ao modo visual para compor sentidos, além do (ii) Enquadramento em relação aos elementos verbais e visuais no texto e ao (iii) Foco, uma vez que diversos elementos coocorrem e alguns deles recebem maior ou menor foco. Por se tratar de uma proposta com base em multiletramentos, são abordadas, ainda, questões sobre atualizações e ampliações do termo letramento, fundamentado no uso da tecnologia da escrita, que, pelas exigências da contemporaneidade, passa a se reconfigurar em multiletramentos necessários em vista das novas linguagens e tecnologias de comunicação e informação. Inseridos na proposta de multiletramentos, abordamos o letramento visual, que pode ser desenvolvido a partir dos elementos verbovisuais nas aberturas das unidades do livro didático sob análise. O que os resultados indicam é o livro didático como um rico suporte para a promoção de multiletramentos e de letramento visual. Esse tipo de análise e seus resultados fornecem contribuições significativas tanto para os multiletramentos e, inseridos neste, o letramento visual, quanto para o ensino de línguas, a formação de professores e questões de multimodalidade em materiais didáticos.
\end{abstract}

PALAVRAS-CHAVE: Análise de Discurso Multimodal Sistêmico-Funcional. Livro didático de Língua Portuguesa. Ensino Fundamental.

ABSTRACT: This text presents an analysis of multimodal elements in the opening of three units of a Portuguese language textbook for elementary school. The starting point for the analysis is the notion of multimodality. Having Systemic-Functional Multimodal Discourse Analysis by Painter, Martin and Unsworth (2013) as our theoretical framework, we present the analysis of aspects related to Intermodal Integration, i.e., the way verbal and visual modes integrate to construe meanings, as well as the Framing in relation to the visual elements in the text, and the Focus, since several elements co-occur and some can be more or less focused. As a multiliteracy-based proposal, questions about updates and expansions of the term literacy, based on the use of writing technology, which, due to the demands of contemporary times, is now reconfigured into necessary multiliteracies in view of the new languages and communication and information technologies. Within a multiliteracy proposal, we approach visual literacy, that can be developed from the visual and verbal elements in the openings of the textbook units under analysis. Results point out that the textbook as a powerful support for promotion multiliteracies and visual literacy. The analysis presented as well as its results provide meaningful contributions both to multiliteracies and, within them, visual literacy, and to language teaching, teacher education and multimodality issues in teaching materials.

KEYWORDS: Systemic Functional Multimodal Discourse Analysis. Portuguese language textbook. Elementary school.

\section{Introdução}

Objetivando refletir sobre a multimodalidade presente nos livros didáticos, acessíveis a todos os estudantes no contexto da educação pública no Brasil, debruçamo-nos, neste texto,

\footnotetext{
${ }^{1}$ Doutor em Linguística Aplicada e Estudos da Linguagem pela PUC-SP. Professor Associado do Departamento de Letras da Universidade Federal de São Paulo. E-mail: orlando.unifesp@gmail.com

${ }^{2}$ Graduada em Pedagogia. Mestranda em Letras/Estudos Linguísticos na Universidade Federal de São Paulo.E-mail: jandcosjand@gmail.com
} 
Volume 14 - Número 2 - ago/dez de 2019

sobre a análise de elementos multimodais de um livro didático, especificamente em seu layout, nas possibilidades de integração entre a linguagem visual e a linguagem verbal. Os livros didáticos, distribuídos em todo o país pelo Programa Nacional do Livro Didático (PNLD), configuram-se como um recurso pedagógico de grande importância no atual cenário educacional público brasileiro. $\mathrm{Na}$ construção dos sentidos, elementos linguísticos e vários outros recursos semióticos são utilizados na tessitura informacional e constituição de novos gêneros textuais e de seus sentidos.

Diante de tal realidade, estabelecemos como foco a reflexão acerca da multimodalidade presente nos livros didáticos e os multiletramentos que indicam a necessidade de alargamento do "letramento tradicional" a fim de dar conta, nos processos de ensino e aprendizagem da língua materna, da multiplicidade de linguagens e das novas exigências requeridas hoje. Para tanto, analisaremos a seção "Abertura de unidade" em três unidades do livro do $3^{\circ}$ ano da coleção Ápis Ensino Fundamental, Anos Iniciais, Língua Portuguesa (BORGATTO; BERTIN; MARCHEZI, 2017), especificamente quanto ao tipo de abordagem dado à linguagem visual e a sua relação com a linguagem verbal. Nossa opção por essa coleção reside no fato de ter sido a mais indicada no PNLD 2019.

Neste recorte, estabelecemos como objetivo geral refletir a respeito da multimodalidade nos textos e sua exploração nos livros didáticos de Português nos anos iniciais do Ensino Fundamental de modo a colaborar com o desenvolvimento dos multiletramentos dos estudantes. Para tal intento, descreveremos a multimodalidade nas referidas seções do LD especificado acima, a partir das relações linguagem visual/linguagem verbal de acordo com as categorias propostas no arcabouço da Análise de Discurso Multimodal Sistêmico-Funcional (ADMSF) por Painter, Martin e Unsworth (2013). Faz-se necessária, contudo, a retomada dos conceitos de letramento e as reflexões sobre novos estudos de letramento e multiletramentos.

O cenário atual para essas áreas tem motivado diversas pesquisas em relação à multimodalidade presente nos livros didáticos de Língua Portuguesa (doravante LDLP) nos anos finais do Ensino Fundamental, no Ensino Médio, para o Português como língua estrangeira, no ensino de Inglês e de Espanhol. No que se refere aos anos iniciais do Ensino Fundamental, entretanto, parece ainda acontecerem em tímida medida, embora haja estudos como os de Rojo (2010), Barros e Costa (2010), Pereira e Terrazan (2011), Amaral e Fischer (2013), dentre outros, que debatam a questão.

De modo geral, os estudos indicam a necessidade de se considerar e intensificar o trabalho com a multimodalidade na produção e recepção de sentidos em vista da diversidade de semioses presentes não somente nos livros didáticos, mas nas culturas em que estamos inseridos. Um dos maiores questionamentos é se a escola está conseguindo acompanhar as céleres inovações no que diz respeito aos subsídios disponibilizados aos estudantes a fim de que estes compreendam os modos e os diversos recursos semióticos imbricados na construção de sentidos presentes nos LDLP. Tomando esse cenário por base, na segunda seção deste texto discutimos o papel da multimodalidade na abertura de unidades de um LDLP para o Ensino Fundamental e como tais materiais podem favorecer, inseridos numa proposta de multiletramentos, o letramento visual. Apresentamos, ainda a teoria que embasa a nossa análise, a ADMSF. São apresentados a metodologia, o corpus utilizado e os passos seguidos na análise na terceira seção. A quarta seção é dedicada à análise do corpus selecionado, onde são apresentadas as aberturas das três das unidades do LDLP que compõem o corpus e a configuração da relação entre a linguagem visual e a linguagem verbal e o modo como tais elementos podem ser utilizados como fonte para que se trabalhe a multimodalidade e o letramento visual. Seguem, por fim, as nossas considerações finais sobre os achados com base na análise. 
Volume 14 - Número 2 - ago/dez de 2019

\section{Breve panorama teórico}

Uma vez que promovemos o diálogo entre distintos elementos teóricos, esta seção aborda a questão do letramento, dos multiletramentos e enfoca o letramento visual, para que, em seguida, apontemos a importância da multimodalidade e a proposta de uma ADMSF e os elementos dela advindos que utilizaremos em nossa análise.

Soares (2017 [1985]) é uma das primeiras autoras no Brasil a debater os termos alfabetismo, alfabetização e letramento. Dado ao foco deste texto, trataremos apenas da questão do letramento, que é, em medida considerável, frequente nas reflexões de docentes e especialistas, mas nem sempre com o mesmo entendimento, já que diversos são os estudos, aprofundamentos e desdobramentos acerca do tema.

Letramento, de acordo com Kleiman (1995, p. 18-19), é "um conjunto de práticas sociais que usam a escrita como tecnologia, em contextos específicos, para objetivos específicos". Para Soares (2004, p. 15), letramento é considerado como a "imersão das crianças na cultura escrita, participação em experiências variadas com a leitura e a escrita, conhecimento e interação com diferentes tipos e gêneros de material escrito".

Uma perspectiva social e etnográfica que se consolidou nos anos 1990, conhecida como Novos Estudos de Letramento (STREET, 1984, 2003), trouxe novos princípios e pressupostos teóricos, como os conceitos de modelo autônomo e modelo ideológico de letramento, e como componentes do fenômeno letramento, as práticas e os eventos de letramento (SOARES, 2003, p, 104). Tais estudos, como sinalizado por Rojo (2010, p. 2) "têm apontado para a heterogeneidade das práticas sociais de leitura, escrita e uso da língua/linguagem em geral em sociedades letradas e têm insistido no caráter sociocultural e situado das práticas de letramento".

Rojo (2010) acrescenta, ainda, que a leitura do texto verbal escrito já não é suficiente, torna-se necessário "colocá-lo em relação com um conjunto de signos de outras modalidades de linguagem (imagem estática, imagem em movimento, som, fala) que o cercam, ou intercalam ou impregnam" (ROJO, 2010, p. 4).

O conceito de letramentos (múltiplos), segundo Rojo (2012, p. 13), indica para "a multiplicidade e variedade das práticas letradas, valorizadas ou não nas sociedades em geral". Já o conceito de multiletramentos refere-se a dois tipos importantes e específicos de multiplicidade presentes nas sociedades contemporâneas, especialmente as urbanas, a saber: "a multiplicidade cultural das populações e a multiplicidade semiótica de constituição dos textos por meio dos quais ela se informa e se comunica" (ROJO, 2012, p. 13).

Inserido em uma proposta mais ampla de multiletramentos, é necessário considerar o letramento visual, que tem adquirido significativa importância nos contextos de ensino. $\mathrm{O}$ letramento visual passou a ser o principal letramento do século 21, conforme apontado por Burmark (2008, p. 5). Este autor ainda reforça que "nossos alunos precisam aprender a processar palavras e imagens" 3 ".

Dada a sua relevância, consideramos o conceito de letramento visual conforme o proposto por Serafini $(2014$, p. 23), como sendo o "processo de geração de significados em operação com composições multimodais, incluindo textos escritos, imagens visuais, e

\footnotetext{
${ }^{3}$... the primary literacy of the twenty-first century is visual. [...] Our students must learn to process both words
} and pictures. 
Volume 14 - Número 2 - ago/dez de 2019

elementos de design, a partir de uma variedade de perspectivas que atendam aos prérequisitos de condições sociais particulares ${ }^{4 \prime}$.

Por essa razão, como fica explícito pela citação de Serafini, as composições multimodais como aquelas presentes nas aberturas do livros didáticos devem ser consideradas, e é crucial também que se considere a multimodalidade presente no cotidiano dos alunos, pois, imersos nessa multiplicidade cultural e semiótica apontada por Rojo (2010), está outro conceito essencial para lidar com os textos em que nela são produzidos e onde circulam: a multimodalidade, também referida como abordagem multimodal. Surgida no âmbito da Semiótica Social de Kress e van Leeuwen ([1996]2006), essa abordagem concebe o texto conforme apontam Gualberto, Pimenta e Santos (2018, p. 15) como a "materialização de um conjunto de modos semióticos que se integram no processo de produção de sentidos".

Não podemos perder de vista nesse cenário teórico, entretanto, as discussões sobre os multiletramentos e as práticas pedagógicas advindas dos debates encetados pelos autores que compuseram o The New London Group (1996), que podem ser considerados precursores de tais discussões em relação aos multiletramentos e sua inserção em contextos pedagógicos.

Relevante também nesse campo de estudos, segundo Gualberto, Pimenta e Santos (2018, p. 18) é o conceito de modo semiótico, compreendido como "um meio material, moldado socialmente, para produzir sentido, como a fala, o gesto, a escrita, a imagem, entre outras possibilidades". Neste entendimento, partido do "princípio de que os textos são constituídos pela integração dos modos semióticos que integram sua composição", concebe-se a multimodalidade como uma "característica constituinte de qualquer texto" (GUALBERTO; PIMENTA; SANTOS, 2018, p. 18), visto que os textos são compostos por diversas linguagens ou recursos semióticos para construir a significação (os modos).

Nesta conjuntura de discussões teóricas sobre as noções de modo, modalidade e multimodalidade, emerge a Análise de Discurso Multimodal Sistêmico-Funcional (ADMSF), que se propõe a compreender a combinação entre as diversas modalidades presentes em um texto multimodal específico, por meio da descrição, a partir da base teórica desenvolvida (as metafunções da linguagem). Nessa proposta, Painter, Martin e Unsworth (2013, p. 13) objetivam tratar os modos como as relações sociais são ativadas a partir de sistemas de significados (DIAS; VIAN JR. 2017, p. 181).

$\mathrm{O}$ arcabouço teórico principal para a análise de imagens a partir de uma perspectiva sociossemiótica no âmbito da LSF é a obra seminal de Kress e van Leeuwen (2006). A proposta dos autores da ADMSF (PAINTER; MARTIN; UNSWORTH, 2013, p. 11) é ampliar e adaptar as propostas de Kress e van Leeuwen para a análise de narrativas em livros infantis ilustrados. Na proposta três são os sentidos analisados: para deflagrar relações sociais, por meio de significados interpessoais; para construir representações, com base na metafunção ideacional e para a análise da composição do espaço visual, com base na metafunção textual. Fica perceptível também que Painter, Martin e Unsworth retomam os termos sistêmico-funcionais originais usados por Halliday (ideacional, interpessoal e textual), em vez dos termos propostos por Kress e van Leeuwen (representacional, interativa e composicional). Com base nessa opção teórica, o foco de nossa análise recairá sobre o layout, ou seja, sobre como se dá a composição do espaço visual nas aberturas das três unidades analisadas.

Para a continuidade das reflexões no limite estabelecido no início deste trabalho - as possibilidades de integração entre linguagem visual e linguagem verbal no espaço visual da abertura das unidades do LDLP -, passemos às contribuições da ADMSF propostas por

\footnotetext{
${ }^{4}$...process of generating meaning in transaction with multimodal ensembles, including written text, visual images, and design elements, from a variety of perspectives to meet the requirements of particular social contexts.
} 
Volume 14 - Número 2 - ago/dez de 2019

Painter, Martin e Unsworth (2013), mais detidamente em alguns elementos que se referem à metafunção textual e à composição deste espaço visual por meio dos sistemas (a) Integração Intermodal, (b) Enquadramento e (c) Foco.

\section{(a) Integração intermodal}

De acordo com a proposta de Painter, Martin e Unsworth (2013), adaptada para a língua portuguesa por Dias e Vian Jr. (2017), são possíveis dois modos de integração entre as imagens e os textos verbais no design dos LDLP, a saber: Integrado ou Complementar.

A partir dessas duas possibilidades, temos que nas ocorrências em que a linguagem verbal ocorre como parte da imagem caracterizam-se como modo Integrado, enquanto, ao contrário, verbiagem e imagem aparecem em espaços distintos, configura-se o modo Complementar. A Figura 1 ilustra as duas opções básicas de layout que podem ocorrer.

Figura 1 - Opções básicas de integração intermodal

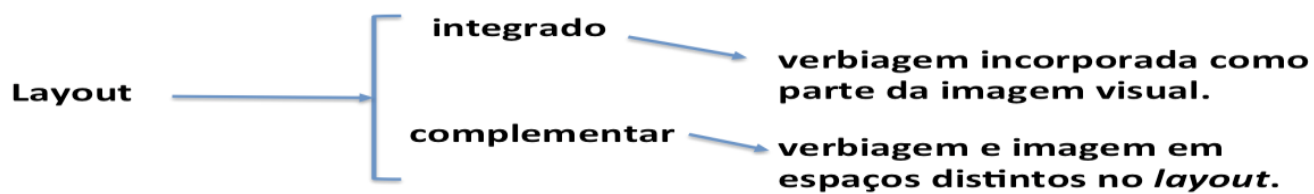

Fonte: Traduzido e adaptado de Painter, Martin e Unsworth (2013, p. 93) por Dias e Vian Jr. (2017, p. 183).

De outro modo, uma unidade visual pode ser composta por dois diferentes layouts, os projetados e os expandidos (PAINTER; MARTIN; UNSWORTH, 2013). A seguir, na Figura 2 , expõem-se as opções básicas de um layout do tipo projetado. Nas tirinhas e charges encontramos os exemplos mais comuns dessas representações, pois as imagens (com os participantes e personagens), os sons (por meio de balões de fala ou pensamento) e as representações sonoras da linguagem (as onomatopéias) entrelaçam-se a tal ponto de exigir a leitura e interpretação da unidade verbo-visual como um todo na construção de seu significado.

Figura 2 - Opções em layout integrado-projetado

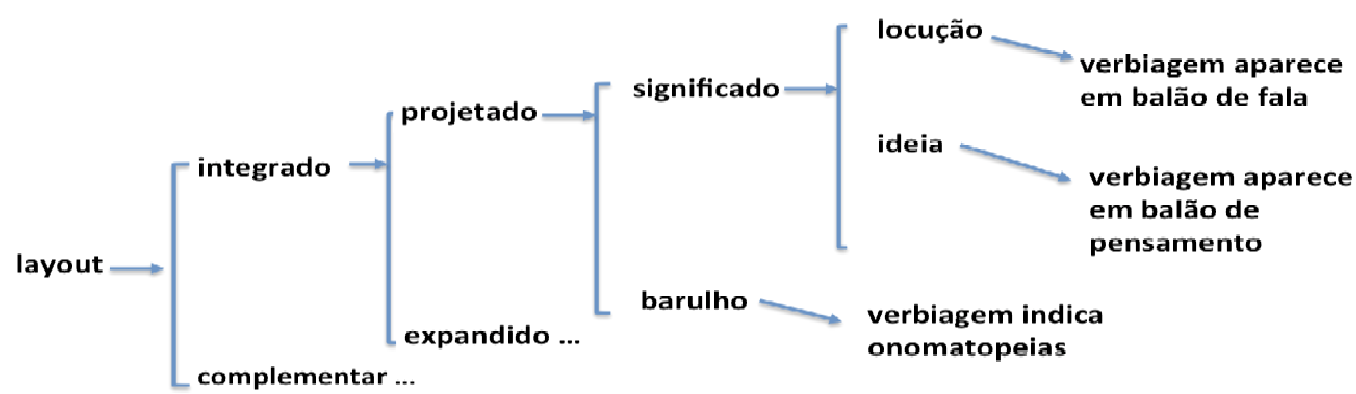

Fonte: Traduzido e adaptado de Painter, Martin e Unsworth (2013, p. 99) por Dias e Vian Jr. (2017, p. 183).

Em outra opção diferente de organização do espaço, encontra-se o layout IntegradoExpandido. Nesse tipo de composição, há duas possibilidades: modalidade Instalada e Reinstalada, conforme exposto na Figura 3. 
Volume 14 - Número 2 - ago/dez de 2019

Figura 3 - Opções em layout integrado-expandido

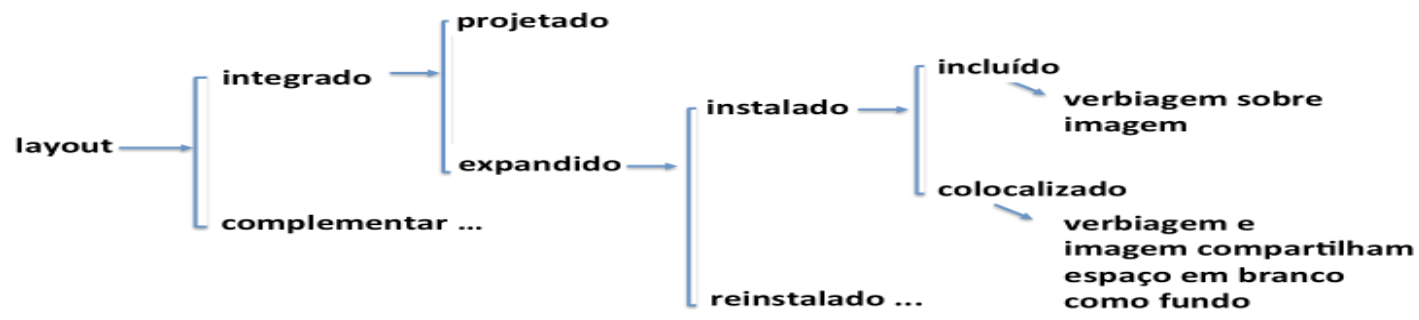

Fonte: Traduzido e adaptado de Painter, Martin e Unsworth (2013, p. 99) por Dias e Vian Jr. (2017, p. 184).

No layout Expandido instalado-incluído, na opção Integrada, as composições criam uma forte fusão entre palavras e imagens, guiando o leitor na leitura como uma única unidade de sentido, de acordo com Painter, Martin e Unsworth (2013, p. 100). Por outro lado, nas composições Instaladas colocalizadas, imagens e palavras são colocadas sobre o mesmo fundo, umas juntamente às outras, entretanto, de acordo com os autores, é possível notar um certo status proeminente para a verbiagem.

De modo diverso, verbiagem e imagem ocupam espaços distintos nos layouts complementares, contudo, considerando maior ou menor destaque no espaço verbo-visual, podem indicar relevância e funções diferenciadas. O estudo de Dias e Vian Jr. (2017, p. 185) revela três possibilidades de ocorrência em livros didáticos de inglês: (1) verbiagem e imagem detêm o mesmo valor; (2) a verbiagem é mais valorizada que a imagem e, por fim, (3) a verbiagem pode ser menos valorizada, com destaque maior para a imagem.

$\mathrm{Na}$ ocorrência da organização vertical, imagem e verbiagem são adjacentes entre si, todavia, devem ocupar, por sua vez, uma a parte superior e outra a parte inferior do espaço verbo-visual. $\mathrm{Na}$ expressão da mensagem, a semiose que se encontra acima da outra, segundo os autores, tem uma relevância maior. Essa organização, em que o verbal ocorre abaixo da imagem, é muito frequente em narrativas infantis, como também nas legendas de vídeos, filmes e pinturas.

Ainda uma terceira combinação verbo-visual pode ocorrer que verbiagem e imagem encontram-se de frente para o observador com dois segmentos verbais interrompidos por uma imagem ou duas imagens interpoladas por um componente verbal. É a organização "sanduíche", conforme apresentada por Dias e Vian Jr. (2017, p. 186) com base em Painter, Martin e Unsworth (2013, p. 96), que pode se apresentar tanto horizontal como verticalmente. Estes autores afirmam que a organização descendente ou vertical é mais comum em narrativas infantis, porém uma e outra pretendem propiciar um ritmo adequado para a leitura.

\section{(b) Enquadramento}

As possibilidades de apresentação das imagens nas páginas dos livros, os enquadramentos e como estes se configuram em relação às imagens nas páginas refletem na unidade do livro como um todo. De modo geral, duas são as opções de tais enquadramentos: os Delimitados, com mais margens e limites bem definidos, e os Não delimitados, com menos margens ou em que as imagens se expandem na página ou em páginas duplas.

(c) Foco

Diversos elementos coocorrem e distribuem-se na composição do layout de uma página. Painter, Martin e Unsworth (2013, p. 110), para sua definição, tomaram como base 
Volume 14 - Número 2 - ago/dez de 2019

estudos acadêmicos das artes plásticas, percepção e fotografia. O modo como os elementos visuais são dispostos na página constituem focos. Estes, por sua vez, possuem padrões composicionais e podem caracterizar, para nossos propósitos neste teto, o LDLP e sua estrutura. Na Figura 4 expõem-se as principais escolhas deste sistema.

Figura 4 - Possibilidades na rede de Foco

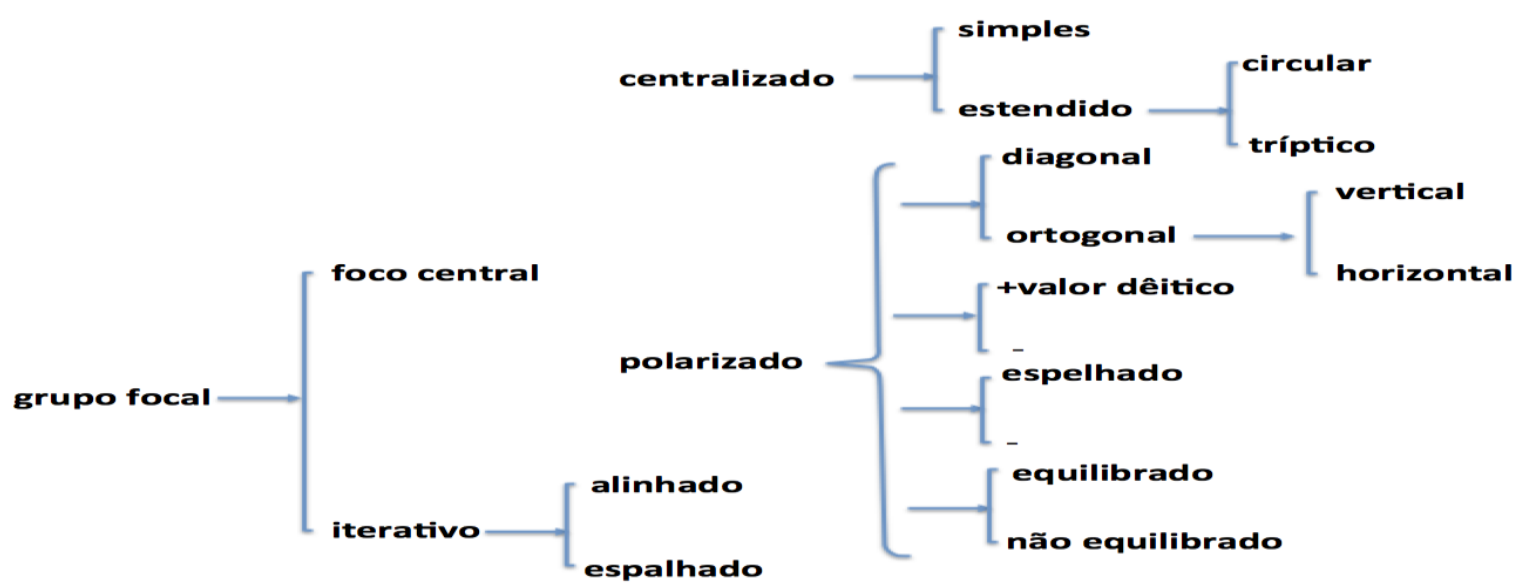

Fonte: Traduzido de Painter, Martin e Unsworth (2013, p. 111) por Dias e Vian Jr. (2017, p. 188).

Os elementos apresentados nas Figuras de 1 a 4 permitem que seja estabelecido o modo como ocorre a integração entre os modos verbal e visual, bem como quais elementos são colocados em foco nas imagens e como estão enquadrados, recursos necessários à análise desses elementos em nosso corpus.

Tomando esses aportes como base de análise, descreveremos, como indicado na Introdução, como ocorrem as integrações entre o verbal e o visual em um livro didático do ensino fundamental. Nosso objetivo é verificar, a partir do corpus selecionado, como tais integrações se organizam, como modo de caracterizá-las para usos em estudos futuros. Antes da análise, entretanto, detalhamos na Seção 3 os passos metodológicos adotados.

\section{Corpus de pesquisa e percurso de análise}

A motivação da escolha dos livros didáticos para a realização deste trabalho dá-se por conta de serem estes formados por textos verbais e visuais, portanto, multimodais e acessíveis a todos os estudantes da escola pública no contexto educacional brasileiro por meio do PNLD, o que os configuram, assim, como recursos de grande importância neste cenário. A coleção Ápis (BORGATTO; BERTIN; MARCHEZI, 2017), foco de nossa análise, foi a mais indicada para o triênio 2019-2021, de acordo com dados disponibilizados pelo FNDE $^{5}$ (Fundo Nacional de Desenvolvimento da Educação). De acordo informações dos autores, disponível no site da editora ${ }^{6}$, a obra objetiva promover "a apropriação do sistema de escrita pelo aluno por meio da aprendizagem significativa, inserindo-o em situações reais de letramento, leitura e escrita por meio de gêneros textuais diversos".

\footnotetext{
${ }^{5}$ Disponível em: https:/www.fnde.gov.br/index.php/programas/programas-do-livro/pnld/dados-estatisticos. Acesso em 24.10.2019.

${ }^{6}$ Disponível em: https://www.aticascipione.com.br/pnld/edital/pnld-2019/obra/2424107/. Acesso em 24.10.2019.
} 
Volume 14 - Número 2 - ago/dez de 2019

Na coleção, a quantidade de unidades temáticas varia entre os anos, distribuídos na seguinte conformidade: no $1^{\circ}$ ano são 22 unidades, nos $2^{\circ}$ e $3^{\circ}$ anos são 12 unidades e para os $4^{\circ}$ e $5^{\circ}$ anos, oito unidades temáticas. Ao longo de toda a coleção, há vasta diversidade de gêneros de circulação e, no que tange à produção de texto escrito, com o detalhamento de diversas etapas envolvidas na produção, desde a motivação até a revisão e escrita final. Pelas restrições de espaço, e devido ao escopo deste texto, delimitar-nos-emos à abertura de três unidades no LDLP do $3^{\circ}$ ano.

As unidades são subdivididas em eixos: leitura, prática de oralidade, produção de texto (oral e escrito), estudos sobre a língua, autoavaliação, ampliação de leitura/intertextualidade, complementos (estes somente para $1^{\circ}$ e $2^{\circ}$ anos). As seções a partir das quais se organizam cada unidade são: Abertura de unidade, Para iniciar, Introdução, Leitura, Interpretação de texto, Prática de oralidade, Aí vem, Produção de texto, Língua: usos e reflexão, Palavras em jogo, Tecendo saberes, Assim também aprendo, O que estudamos, Projeto de leitura, Uso do dicionário.

Como já citado anteriormente, nosso foco delimita-se na análise do espaço verbovisual de unidades que lidam com gêneros narrativos, parte de uma estudo maior em andamento. Desse modo, selecionamos três unidades no LDLP do $3^{\circ}$ ano que se inserem na família dos gêneros narrativos, a saber: a unidade 3, que aborda o gênero Fábula; a unidade 6 , cujo foco de abordagem é o Conto maravilhoso; e a unidade 7, que tem por foco o Conto popular. A partir da seleção das páginas de abertura dessas três unidades, procedemos a análise a partir dos elementos expostos na Seção 2, conforme proposto por Painter, Martin e Unsworth (2013) e adaptado para a língua portuguesa por Dias e Vian Jr. (2017).

\section{Análise da integração entre linguagem visual e linguagem verbal}

Como forma de discutir e apresentar as diferentes maneiras pelas quais os sentidos são construídos e transmitidos aos alunos/leitores pelos elementos verbo-visuais presentes nas aberturas das unidades do livro didático analisado, apresentamos a seguir, como indicado na seção de metodologia, a abertura de três unidades do referido material didático, com base nas escolhas de Integração Intermodal, Enquadramento e Foco propostas pela ADMSF preceituada por Painter, Martin e Unsworth (2013) e apresentadas na segunda seção. A descrição dessas escolhas pode não só promover multiletramentos e, mais especificamente, o letramento visual, mas também fornecer relevantes subsídios para a formação de professores no que diz respeito ao uso de materiais didáticos para o tratamento das imagens e suas relações com o texto verbal, como apresentamos nas análises a seguir.

Como já indicado anteriormente, este livro didático em específico foi escolhido por ser o mais adotado no país, o que significa que uma quantidade significativa de estudantes terá acesso a tal material e as imagens nele apresentadas devem também ser utilizadas nas aulas, como forma de leitura em sentido mais amplo que aquela restrita apenas às palavras.

A composição do layout das páginas de abertura das unidades temáticas chama a atenção dos leitores por sua configuração, uma vez que antecipam o tema da unidade e estão diretamente relacionadas ao gênero textual que será foco da unidade, resgatando elementos da experiência dos alunos ou elementos a serem inseridos em sua vida escolar.

O enquadramento das imagens é do tipo Não Delimitado em que, além das ilustrações tomarem toda a página, expandem-se para a seguinte, em páginas duplas, como ilustra a Figura 5. Já os dois espaços com informações verbais são do tipo Delimitado.

Como é possível visualizar na Figura 5, há utilização de linguagem verbal em três ocorrências, sobrepostas sobre a imagem: uma para o número da unidade e seu título, no canto 
Volume 14 - Número 2 - ago/dez de 2019

superior esquerdo; uma segunda, logo abaixo do título e número da unidade, intitulada "Nesta unidade você vai...", em fonte verde, sobre um fundo branco são inseridos os objetivos da unidade, que serão desenvolvidos em forma de diferentes atividades de compreensão escrita e em forma de produção escrita; além dessas, no canto inferior direito, utiliza-se a linguagem verbal para perguntas relacionadas ao tema a se desenvolver, no intuito de antecipar e mobilizar conhecimentos prévios acerca do tema em foco. Nestas páginas duplas ocorre notável valorização da imagem, entretanto, com o uso de recursos tipográficos, cores, formas e fontes e formato padrão em toda a coleção.

Figura 5 - Abertura da unidade 3

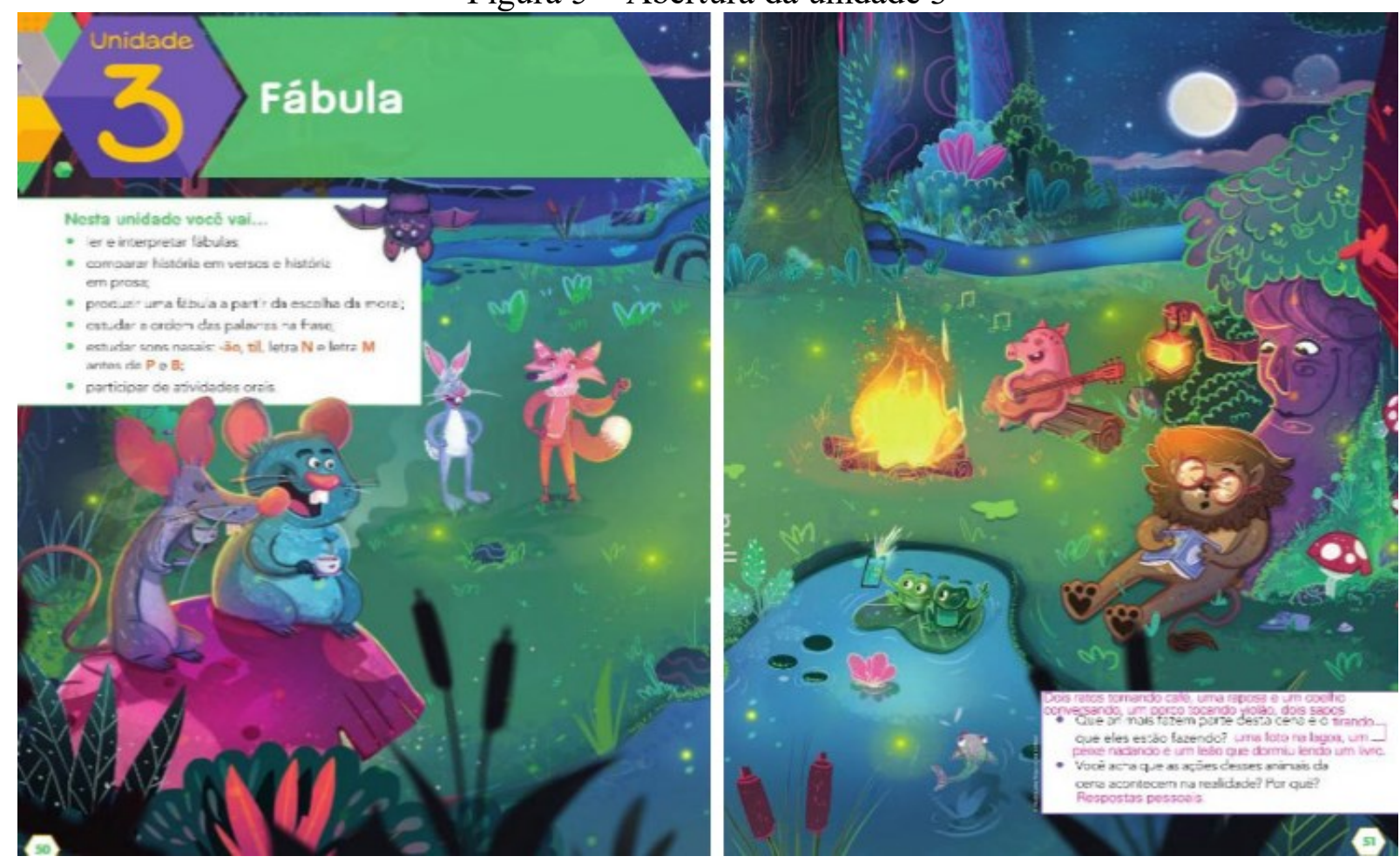

Fonte: Borgatto, Bertin e Marchezi (2017), $3^{\circ}$ ano, p. 50-51

Na Figura 5, ainda, sobre o gênero discursivo Fábula, também é possível perceber a presença de elementos típicos das fábulas: animais interagindo de forma humanizada, em conversas, ao redor da fogueira, lendo, em brincadeiras, enfim, caracterizando o elemento definidor do gênero fábula que será abordado na unidade. A necessária exploração desses elementos visuais permite não só suscitar experiências e conhecimentos de mundo dos alunos, mas também incrementar suas reflexões sobre seu conhecimento prévio, já que fábulas são elementos comuns na infância, veiculadas em filmes, desenhos animados, histórias em quadrinhos, jogos eletrônicos, roleplaying games e diversas outras possibilidades de meios que podem circular nos distintos contextos em que convivem e interagem os alunos.

Do ponto de vista das possibilidades do sistema de Integração Intermodal, conforme opções apresentadas na Figura 1, com suas ampliações nas Figuras 2 e 3, é possível vislumbrarmos um layout complementar, em que as três ocorrências de linguagem verbal são sobrepostas à imagem, mas não fazem parte dela. Essa distinção entre imagem e verbiagem é marcada pelas cores distintas do título da unidade e dos dois espaços com conteúdos verbais.

Em relação ao Enquadramento, as opções possíveis, como apresentamos na seção 2(b), são Enquadramento Delimitado e a Não Delimitado. O que observamos na Figura 5 é a 
Volume 14 - Número 2 - ago/dez de 2019

apresentação da imagem expandida pelas duas páginas em Enquadramento Não Delimitado e, em Enquadramentos Delimitados, sobrepostas à imagem, as três ocorrências de texto verbal.

O Foco, por fim, revela que a imagem está centrada na fogueira, ao redor da qual os demais elementos circulam e seu brilho está refletido e distribuído pela imagem em diferentes pontos de luz. Trata-se, portanto, como opções apresentadas na Figura 4, de um foco central (a fogueira), com opção Centralizado, e que é estendido pelos pontos de luz na imagem.

A conjunção dos elementos dos três sistemas da composição do espaço visual, a saber: de Integração Intermodal, de Enquadramento e de Foco, compõe um único texto verbo-visual, que funciona para abertura da unidade e, por essa razão, constrói sentidos, conforme ilustra a Figura 5, que podem e devem ser explorados pelos professores com fins distintos, mas, principalmente, para promoção de letramento visual, além de outras possibilidades de multiletramentos possíveis.

Na prática de sala de aula na educação básica, o trabalho com os elementos verbovisuais permite que se vá construindo noções importantes para o letramento visual e para a produção de sentidos junto aos alunos, permitindo despertar, por exemplo, a questão das relações entre os elementos verbais e visuais e como estes, em conjunto, constroem sentidos para os textos/gêneros sendo trabalhados. Uma das importantes contribuições dessa abordagem, ainda, é levar os leitores em formação a perceberem que as imagens não estão lá por acaso, por mera questão decorativa. Seu papel está na construção dos significados veiculados pela integração entre texto e imagem.

Apresentamos, a seguir, a Figura 6, de abertura da Unidade 6, que possui a mesma configuração de layout definido na Figura 5. Nessa unidade, aborda-se o gênero Conto maravilhoso.

Figura 6 - Abertura da unidade 6

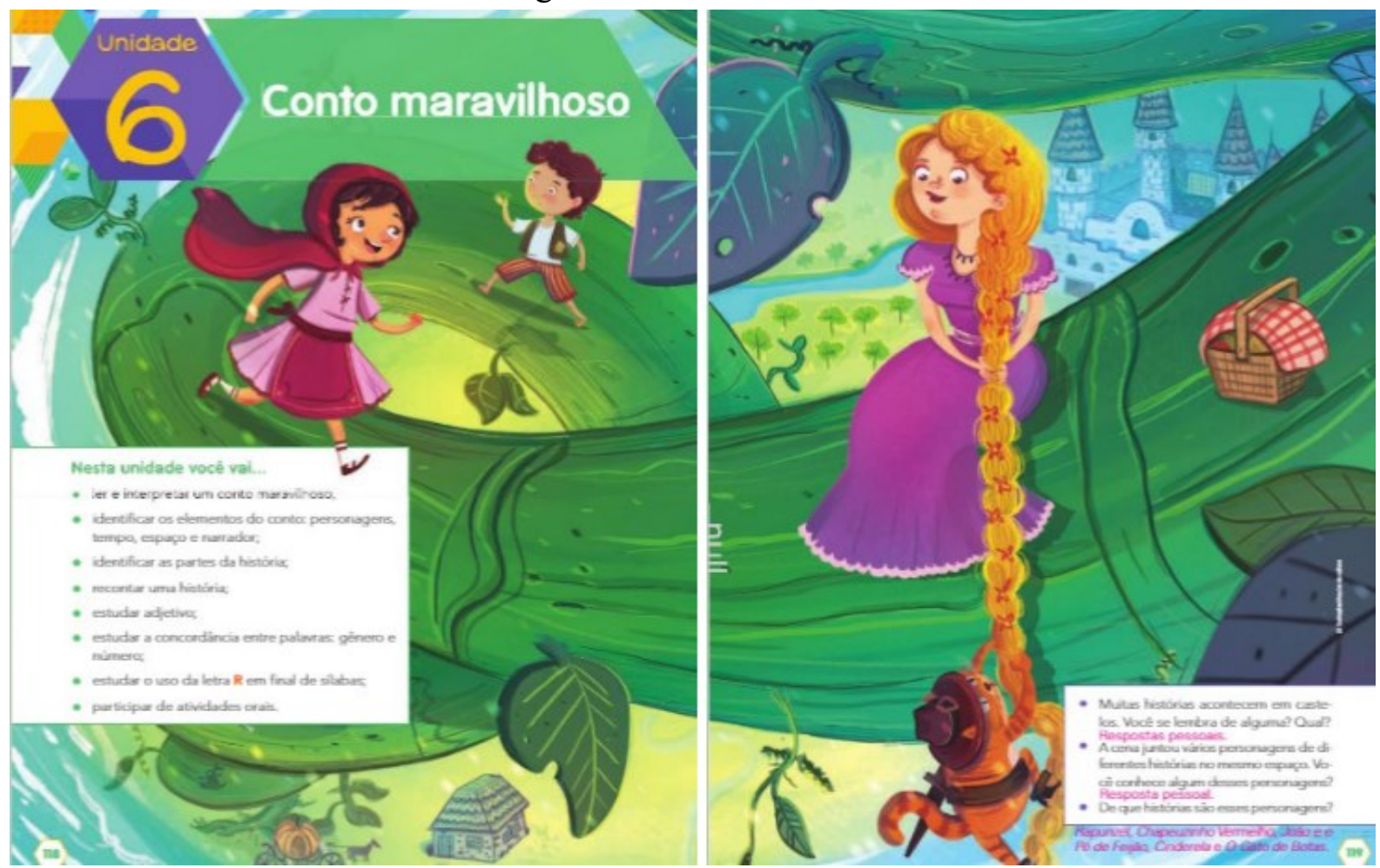

Fonte: Borgatto, Bertin e Marchezi (2017), $3^{\circ}$ ano, p. 118-119 
Volume 14 - Número 2 - ago/dez de 2019

$\mathrm{Na}$ imagem, estão presentes de forma interativa, e como participantes de um mesmo evento, diferentes personagens de distintos contos maravilhosos que, possivelmente, circulam na vida dos alunos.

O Foco central da imagem é a figura de Rapunzel, em primeiro plano, e em enquadramento central na página da direita, tendo o Gato de Botas escalando suas tranças, e, caminhando em sua direção, supostamente escalando o pé de feijão de outro conto maravilhoso, é possível distinguir Chapeuzinho Vermelho e João, do conto João e o Pé de Feijão, cuja árvore, supostamente, está sendo escalada e onde se desenvolvem as ações dos personagens apresentados.

Ainda em relação à imagem representada pela Figura 6, vislumbra-se, como pano de fundo, e em plano diferente e, portanto, conforme as possibilidades na rede de Foco, apresentadas na Figura 4, na opção centralizado e estendido, podem-se vislumbrar castelo, casa, rio, também elementos típicos de contos maravilhosos.

A Integração entre os modos escrito e visual é realizada da mesma forma como está organizado para a Unidade 3 apresentada na Figura 5. Sinalizamos apenas para o ligeiro deslocamento vertical do quadro com o conteúdo do que será abordado na unidade, como pode ser verificado na Figura 6.

A análise desses dados, assim trazem implicações significativas para o letramento visual e a formação crítica do leitor, levando os alunos a perceberem seus papeis como leitores e como os elementos verbais e visuais integram-se para construir significados nos textos que leem, instaurando a prática de que o leitor tem papel bastante importante na coconsrução dos sentidos dos textos presentes em seu livro didático e, consequentemente, podem ser transpostos para a sua ciada cotidiana, impregnada de textos e imagens.

A terceira composição verbo-visual selecionada para análise é a Unidade 7, representada na Figura 7, em que se aborda o gênero Conto popular. As características da Integração Intermodal, Enquadramento e Foco apresentam as mesmas características daquelas apresentadas nas Figuras 5 e 6 . As próprias imagens apresentadas encaminham para a questão do conto popular, já que traz a representação de um grupo de pessoas, com crianças acompanhadas por adultos sentados em um espaço público, ouvindo um senhor, cuja opção de Foco é central da imagem, ao redor da qual as demais gravitam que, supostamente, conta uma história ao grupo.

Figura 7 - Abertura da unidade 7

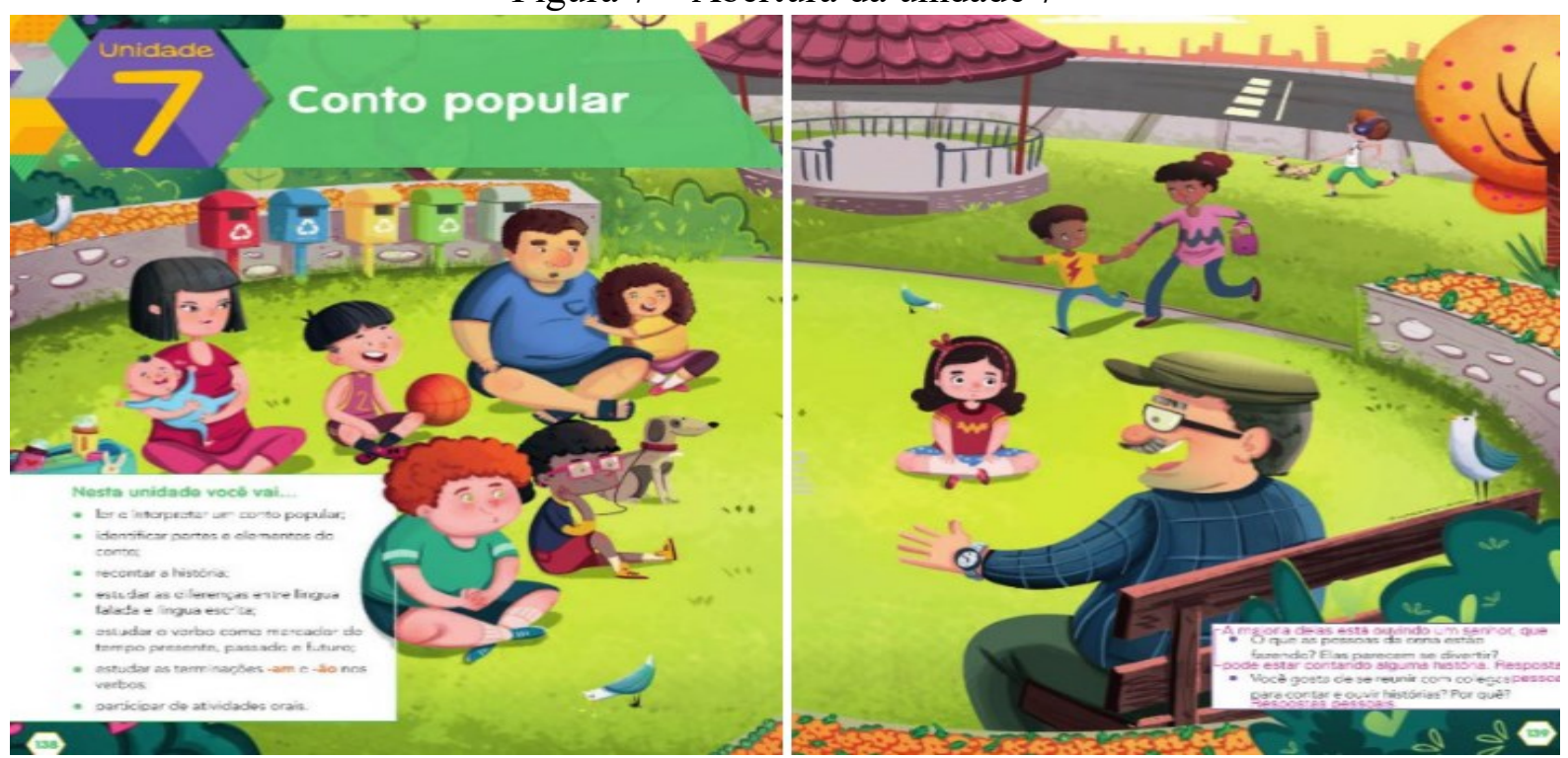

Fonte: Borgatto, Bertin e Marchezi (2017), $3^{\circ}$ ano, p. 138-139 
Volume 14 - Número 2 - ago/dez de 2019

$\mathrm{O}$ que se verifica na abertura das unidades a partir das imagens representadas nas Figuras 5, 6 e 7, desse modo, são dois elementos importantes para o ensino fundamental e para o trabalho do professor em sala de aula e para a formação do leitor crítico e seu letramento visual: (i) primeiramente, as figuras evidenciam a total integração entre texto verbal e texto visual. Como se pode verificar, há partes das imagens que se integram totalmente ao espaço delimitado para o texto verbal, apresentados em fundo branco, com o adentramento da imagem no espaço do texto verbal. Trata-se, portanto, pela perspectiva da ADMSF aqui apresentada, de uma composição instalada, integrando texto verbal e texto visual, construindo sentidos para os leitores e, para o professor, tais composições podem ser utilizadas no trabalho em sala de aula para uma pedagogia de multiletramentos. Em segundo lugar, essas aberturas têm por função oferecer uma contextualização do tema a ser abordado em cada uma das unidades. Trata-se, portanto, de um rico material a ser explorado visualmente, funcionando como elemento deflagrador do conhecimento de mundo dos alunos, uma vez que, pela simples visualização das imagens, é possível discutir os sentidos construídos pelas relações entre os elementos, como também quais práticas sociais relacionadas às vidas dos alunos as imagens representam ou a ela estão associadas.

$\mathrm{O}$ que pode ser observado nas configurações aqui apresentadas por meio das Figuras de 5 a 7 vão ao encontro do que preceituam Martin e Rose $(2012$, p. 3) para livros didáticos em língua inglesa no contexto australiano, segundo os autores:

No mundo de língua inglesa, esses livros evoluíram nas últimas décadas a partir de livros envolvendo principalmente a linguagem escrita (por exemplo, Martin 1947), com algumas ilustrações, gráficos e diagramas, em direção a apresentações no estilo de revistas multimodais. Nesses textos multimodais, imagens de vários tipos e suas legendas moldam o layout das páginas ou páginas duplas, circunscrevendo a linguagem escrita envolvida. ${ }^{7}$

Observamos o mesmo fenômeno no corpus aqui analisado, já que os livros publicados no Brasil e inscritos no PNLD apresentam, conforme já observado em outros estudos, como por exemplo para os livros didáticos de língua inglesa (DIAS; VIAN JR, 2017; MORENO JR., 2018) e de língua portuguesa (BITENCOURT, 2018; BITENCOURT; VIAN JR, 2019), as mesmas características com ilustrações envolvendo textos verbais, caracterizando-os no mesmo formato de revistas da grande mídia. Estudos futuros podem se debruçar sobre as razões para tais escolhas no contexto brasileiro e do PNLD, além de outras questões relacionadas.

\section{Considerações finais}

Nosso principal objetivo neste texto foi desenvolver uma análise preliminar da abertura de três unidades de um livro didático do ensino fundamental, área pouco pesquisada no campo dos estudos de multimodalidade e de livros didáticos.

A análise apresentada recaiu sobre três sistemas da ADMSF de Painter, Martin e Unsworth (2013), mais especificamente, os significados textuais, relacionados ao modo como o layout é composto, a saber: a Integração Intermodal, o Enquadramento e o Foco. No

\footnotetext{
${ }^{7}$ In the English speaking world these textbooks have evolved over the past few decades from books involving mainly written language (e.g. Martin 1947) with a few illustrations, graphs and diagrams, towards multimodal magazine style presentations. In such multimodal texts, images of various kinds and their captions shape the layout of pages or double page spreads, circumscribing the written language involved.
} 
Volume 14 - Número 2 - ago/dez de 2019

entanto, embora indicativos de muitos elementos sobre o texto verbo-visual e sua composição, esses três elementos podem ser complementados, pois a construção dos sentidos nas aberturas das unidades dependerá também de que essa proposta esteja inserida numa perspectiva mais ampla de multiletramentos e, ainda, o trabalho com o letramento visual com os alunos.

Nosso foco no letramento visual deveu-se principalmente ao fato de que as experiências de sala de aula, bem como relatos de professores, vêm revelando que as imagens nos livros didáticos são geralmente ignoradas e, como foi possível perceber pelas análises, elas são uma fonte bastante significativa e os significados só são efetivamente construídos pela integração entre o visual e o verbal, que devem ser vistos como um texto, formando um todo coeso e coerente entre linguagens verbais e visuais.

A partir das análises apresentadas, emerge o questionamento sobre qual a relevância da descrição de como se configuram as relações entre o texto verbal e o texto visual nos livros didáticos no ensino fundamental e, daí, outros pontos merecem ser considerados. Esse tipo de análise permite que se desvelem aspectos dos elementos visuais, reforçando o que propõe Burmark (2008, p. 5) de que "para serem letrados visualmente, eles [os alunos] precisam aprender a 'ler' (consumir/interpretar) imagens e 'escrever'(produzir/usar) comunicações visualmente ricas ${ }^{8 "}$.

Da mesma forma, temos que levar também em consideração as políticas editoriais e como estas se materializam nos livros didáticos que circulam nas escolas, uma vez que os professores deverão estar aptos a não apenas manusear os livros, mas também abordar e explorar os diversos aspectos para a construção dos sentidos nos textos utilizados em sala de aula e a integração entre linguagem verbal e linguagem visual é uma realidade.

Ainda emerge outra questão bastante relevante: como professores do ensino básico que não receberam ou não tenham tido contato com tais teorias, podem promover o letramento visual de seus alunos? Embora se trate de uma questão bastante ampla e complexa, ama das formas de acesso pode ser a divulgação de resultados de pesquisas, como o que ora apresentamos. Faz-se necessário, também, ofertar cursos de formação continuada aos professores em serviço para que possam ter acesso a tais elementos, uma vez que texto e imagem fazem parte de seu universo e de seus alunos, já que, no mundo atual, onde as tecnologias móveis imperam, a integração entre texto e imagem é mais do que presente e, por essa razão, deve ser abordada no ensino. Podemos pensar, ainda, na divulgação desses resultados por recursos multi e hipermidiáticos.

Embora tenhamos nos detido em alguns enfoques de três unidades do livro do $3^{\circ}$ ano da coleção Ápis Língua Portuguesa, no que diz respeito aos elementos constitutivos de gêneros narrativos (fábula, conto maravilhoso e conto popular) nas seções Abertura de unidade, pode-se verificar que há uma significativa quantidade de recursos multimodais no layout dessas seções, geralmente consideradas apenas como um elemento decorativo.

Estes recursos estão presentes na cultura e nas sociedades contemporâneas e, conforme adverte Rojo (2012), é mais que necessário investir em novos e multiletramentos. Os estudos obtidos com este trabalho indicam que o LDLP analisado é um importante recurso com aspectos multimodais a serem trabalhados em aula. Mas deve-se tomar o cuidado de não tratar a multimodalidade como um fenômeno à parte ou uma teoria encapsulada em si mesma. Pelo contrário, devemos ter em mente que se trata de um elemento sempre presente na vida cotidiana e que, com as novas tecnologias e políticas editoriais, tornam-se cada vez mais presentes também nos livros didáticos e, com isso, deve ser utilizada como forma de promover o letramento multimodal entre os estudantes.

\footnotetext{
${ }^{8}$ To be visually literate, they must learn to "read" (consume/interpret) images and "write" (produce/use) visually rich communications".
} 
Volume 14 - Número 2 - ago/dez de 2019

Encerramos este texto retomando o que Painter, Martin e Unsworth (2013, p.1) afirmam sobre os livros ilustrados para crianças, uma vez que esses autores sinalizam para o fato de que tais livros podem ter seu papel identificado "como um meio fundamental de aprendizagem em letramento, literatura e valores sociais, o que, por sua vez, significa que a forma como são construídos para atingir esses fins é uma questão educacional importante ${ }^{9 "}$.

Pela análise aqui empreendida, bem como resultados sobre estudos de imagens em outros livros didáticos, como aqueles apontados na seção anterior, é possível fazer a mesma afirmação para as imagens utilizadas nas aberturas das unidades, tratando-se de uma relevante questão educacional, que podem ser ampliadas em estudos futuros, principalmente pelo diferencial de os livros didáticos já fazerem parte do universo educacional. Trata-se, portanto, de um redirecionamento de olhares, passando a encará-los como rica fonte de produção de multiletramentos.

\section{Referências}

AMARAL, T.T.; FISCHER, A. Abordagem da imagem em um livro didático voltado para a alfabetização: perspectivas de letramento visual. Bakhtiniana: Revista de Estudos do Discurso. São Paulo, 8 (2): 5 - 23, Jul./Dez. 2013. Disponível em $<$ https://revistas.pucsp.br/bakhtiniana/article/view/14016>. Acesso em 20.06.2019.

BARROS, C.G.P.; COSTA, E.P.M. Os gêneros multimodais em livros didáticos: formação para o letramento visual? Bakhtiniana: Revista de Estudos do Discurso. São Paulo, 7 (2): 38 56, Jul./Dez. 2012. Disponível em < https://revistas.pucsp.br/bakhtiniana/issue/view/893> Acesso em 20.06.2019.

BITENCOURT, A.P. A multimodalidade na abertura de unidades e de capítulos em um livro didático de Língua Portuguesa. Dissertação de mestrado em Letras. Universidade Federal de São Paulo, 2018.

BITENCOURT, A.P.; VIAN JR., O. Multimodalidade em aberturas de capítulos de um livro didático de Língua Portuguesa. Revista Intercâmbio, volume 40, p. 01-21, 2019. BORGATTO, A.M.T.; BERTIN, T.C.H.; MARCHEZI, V.L.C. Ápis: Língua Portuguesa. $3^{\circ}$ ano. São Paulo: Ática, 2017.

BURMARK, L. Visual literacy: what you get is what you see. In: FREY, N.; FISHER, D. (Ed). Teaching visual literacy: using comic books, graphic novels, anime, cartoons, and more to develop comprehension and thinking skills. California: Corwin Press, 2008. p. 5-25. DIAS, R.; VIAN JR., O. Análise de Discurso Multimodal Sistêmico-Funcional de livros didáticos de inglês do ensino médio da educação pública. Signum: Estudos Linguísticos, Londrina, n. 20/3, p. 176 -212, dez. 2017.

GUALBERTO, C.L.; PIMENTA, S.M.O.; SANTOS, Z.B. Leitura e produção textual no contexto acadêmico: práticas e reflexões a partir da multimodalidade e da Semiótica Social. In GUALBERTO, C.L.; PIMENTA, S. M. O.; SANTOS, Z. B. (Orgs.) Multimodalidade e ensino: múltiplas perspectivas. São Paulo: Pimenta Cultural, 2018.

KLEIMAN, A.B. (Org.). Os significados do letramento: uma nova perspectiva sobre a prática social da escrita. Campinas: Mercado de Letras, 1995.

KRESS, G.; VAN LEEUWEN, T. Reading images: the grammar of visual design. London and NY: Routledge, [1996]2006.

MARTIN, J.R.; ROSE, D. Genres and texts: living in the real world. Indonesian Journal of SFL, 1 (1), 1-21, 2012. Disponível em: https://www.readingtolearn.com.au/wp-

9 ... as a key means of apprenticeship into literacy, literature and social values, which in turn means that how they are constructed to accomplish these ends is an important educational question. 
Volume 14 - Número 2 - ago/dez de 2019

content/uploads/2016/01/Genres-and-texts-living-in-the-real-world.pdf. Acesso em 21.10.2019.

MORENO JR. E.V. Multimodalidade no Caderno do Aluno de Inglês da rede pública de

São Paulo: um estudo à luz da Análise de Discurso Multimodal Sistêmico-Funcional.

Dissertação de mestrado em Letras. Universidade Federal de São Paulo, 2018.

PAINTER, C.; MARTIN, J.R.; UNSWORTH, L. Reading visual narratives: Image analyses of children's picture books. Sheffield \& Bristol, CT: Equinox, 2013.

PEREIRA, A.G.; TERRAZAN, E.A. A multimodalidade em textos de popularização da ciência: contribuições para o ensino de ciências para crianças. Ciência \& Educação, volume 17, no. 2, pp. 489-503, 2011.

ROJO, R.H.R. Letramentos escolares: coletâneas de textos nos livros didáticos de língua portuguesa. Perspectiva, v. 28, n. 2, p. 433 - 465, Jul./Dez. 2010. Disponível em

$<$ https://periodicos.ufsc.br/index.php/perspectiva/article/view/2175-

795X.2010v28n2p433/18444> Acesso em 20.06.2019.

ROJO, R. Pedagogia dos multiletramentos: diversidade cultural e de linguagens na escola. In: ROJO, R.; MOURA, E. (Orgs.). Multiletramentos na escola. São Paulo: Parábola Editorial, 2012.

SERAFINI, F. Reading the visual: an introduction to teaching multimodal literacy. London: Teachers College Press, 2014.

SOARES, M. Alfabetização e letramento. São Paulo: Contexto, 2017 [1985].

SOARES, M. Letramento: um tema em três gêneros. 2ed. Belo Horizonte: Autêntica, 2004

STREET, B. Literacy in theory and practice. Cambridge; New York and Melbourne:

Cambridge University Press, 1984.

STREET, B. What's "new" in New Literacy Studies? Critical approaches to literacy in theory and practice. Current Issues in Comparative Education, 5 (2): pp. 77-91, 2003.

THE NEW LONDON GROUP. A Pedagogy of Multiliteracies: designing social futures.

Harvard Educational Review, v. 66, n. 1, p. 60-92, 1996. Disponível em:

$<$ http://vassarliteracy.pbworks.com/f/

Pedagogy + of + Multiliteracies_New+London+Group.pdf $>$. Acesso em: 20.06.2019.

WEBER, M.; SANTOS, L.I.S. Textos multimodais em sala de aula de Língua Portuguesa.

Revista de Letras Norte@mentos Estudos Linguísticos, Sinop, v. 9, n. 19, p. 98 - 113, Jul/Dez. 2016. Disponível em

$<$ http://sinop.unemat.br/projetos/revista/index.php/norteamentos/article/view/2402/1814>

Acesso em 20.06.2019. 